\title{
MicroRNA-93 regulates angiogenesis in peripheral arterial disease by targeting CDKN1A
}

\author{
XIAOJUN SHU ${ }^{1,2^{*}}$, YOUJUN MAO ${ }^{2 *}$, ZHENGFEI LI $^{1}$, WENHUI WANG ${ }^{1}$, \\ YAOWEN CHANG ${ }^{1}$, SHENGYE LIU ${ }^{1}$ and XIAO-QIANG LI ${ }^{2}$ \\ ${ }^{1}$ Department of Interventional Radiology, The First Hospital of Lanzhou University, Lanzhou, Gansu 730000; \\ ${ }^{2}$ Department of Vascular Surgery, The Second Affiliated Hospital of Soochow University, Suzhou, Jiangsu 215000, P.R. China
}

Received January 25, 2018; Accepted July 30, 2018

DOI: $10.3892 / \mathrm{mmr} .2019 .10196$

\begin{abstract}
MicroRNAs (miRNAs) are considered to be critical mediators of gene expression with respect to tumor progression, although their role in ischemia-induced angiogenesis is poorly characterized, including in peripheral arterial disease (PAD). Furthermore, the underlying mechanism of action of specific miRNAs in PAD remains unknown. Reverse transcription-quantitative polymerase chain reaction analysis revealed that microRNA-93 (miR-93) was significantly upregulated in patients with PAD and in the EA.hy926 endothelial cells in response to hypoxia. Additionally, miRNA (miR)-93 promoted angiogenesis by enhancing proliferation, migration and tube formation. Cyclin dependent kinase inhibitor $1 \mathrm{~A}$ (CDKN1A), verified as a potential target gene of miR-93, was inhibited by overexpressed miR-93 at the protein and mRNA expression levels. Furthermore, a hind-limb ischemia model served to evaluate the role of miR-93 in angiogenesis in vivo, and the results demonstrated that miR-93 overexpression enhanced capillary density and perfusion recovery from hind-limb ischemia. Taken together, miR-93 was indicated to be a promising target for pharmacological regulation to promote angiogenesis, and the miR-93/CDKN1A pathway may function as a novel therapeutic approach in PAD.
\end{abstract}

\section{Introduction}

Peripheral arterial disease (PAD) is an atherosclerotic disease, which affects the arteries of the limbs. It occurs via a complex process including endothelial dysfunction in animals (1) and humans (2), lipid metabolic disturbance, thrombosis and

Correspondence to: Dr Xiao-Qiang Li, Department of Vascular Surgery, The Second Affiliated Hospital of Soochow University, 1055 Sanxiang Road, Suzhou, Jiangsu 215000, P.R. China

E-mail: lixiaoqiang011@163.com

${ }^{*}$ Contributed equally

Key words: microRNA-93, angiogenesis, peripheral arterial disease, hind-limb ischemia, cyclin dependent kinase inhibitor $1 \mathrm{~A}$ inflammation (3). It has been reported that the incidence of PAD is as high as $15-20 \%$ in people $>70$ years old $(4,5)$, with the prevalence of intermittent claudication (IC) rising to $\sim 6 \%$ in people $>60$ years old (6). PAD is usually associated with atherosclerosis in the whole-body vasculature and is considered to be a principal cause of mortality worldwide. Although there have been multiple studies conducted regarding relevant risk factors in PAD, the underlying epigenetic mechanism is poorly characterized (7-9).

MicroRNAs (miRNAs) are short noncoding RNAs that are involved in the mediation of human gene expression by binding to mRNA, in addition to suppressing protein synthesis (7). There are no fewer than 1,500 human miRNAs in the miRBase database, which serve a critical role in the post-transcriptional modification of gene expression via targeting of the 3'-untranslated region (UTR) of specific mRNAs (8), thereby affecting various cellular processes in embryonic development and disease conditions (9-11). Previous studies have indicated that the determination of miRNA expression in patients with PAD may serve a prognostic and diagnostic role in the future $(12,13)$.

Recently, regarding the study of tumor and hind limb ischemia, miRNA (miR)-93 has been considered to be able to mediate angiogenesis in various molecular pathways $(14,15)$. miR-93 is a member of the miRNA-106b 25 cluster, and has been demonstrated to serve a key oncogenic role by regulating cell proliferation, migration, the cell cycle and tube formation (16-18). However, the association between miR-93 and PAD remains unknown and the target gene of miR-93 in PAD has not been fully characterized.

The present study determined the expression levels of miR-93 in the serum of patients with PAD and investigated the function of miR-93 in angiogenesis in a cell model and in an ischemic hind-limb mouse model. In addition, the study aimed to identify the underlying downstream targets involved in PAD.

\section{Materials and methods}

Clinical samples. A total of 146 patients with PAD (79 male and 67 female) with a mean age of $58.9 \pm 9.8$ years were admitted to the 1st Hospital of Lanzhou University (Lanzhou, China) to receive drug therapy and other ancillary treatment. In addition, 
32 normal control subjects (18 male and 14 female) with a mean age of 57.6 \pm 8.1 years were recruited. The ankle brachial index (ABI) was used to assess the severity of PAD (19). The blood samples from the PAD patients at the time of admission and from the controls were collected and centrifuged at $200 \mathrm{x} \mathrm{g}$ for $10 \mathrm{~min}$ at $4^{\circ} \mathrm{C}$ to harvest the separated serum, and stored at $-80^{\circ} \mathrm{C}$ for further analysis. Written informed consent was obtained from all patients and the experiment was approved by the ethics committee of 1st Hospital of Lanzhou University (Lanzhou, China).

Reverse transcription-quantitative polymerase chain reaction $(R T-q P C R)$. RT-qPCR analyses of miR-93 were performed on patient serum using specific TaqMan assays (Life Technologies; Thermo Fisher Scientific, Inc., Waltham, MA, USA) as previously described (20). In addition, RNA was isolated from EA.hy926 cells to analyze the cyclin dependent kinase inhibitor 1A (CDKN1A) mRNA expression and the miRNA-93 expression using TaqMan assays (Life Technologies; Thermo Fisher Scientific, Inc.) as previously described (21). PCR primer sequences were obtained from previously published studies $(20,21)$.

Cell culture and transfection. EA.hy926 endothelial cells (American Type Culture Collection, Manassas, VA, USA) were cultured in Dulbecco's modified Eagle's medium (Gibco; Thermo Fisher Scientific, Inc.), 10\% fetal calf serum (Gibco; Thermo Fisher Scientific, Inc.), $1 \%$ glutamine, $1 \%$ nonessential amino acids, and penicillin $(100 \mathrm{U} / \mathrm{ml})$ at $37^{\circ} \mathrm{C}$ and $5 \% \mathrm{CO}_{2}$ under humidified conditions. The cells were cultured in hypoxic conditions when the oxygen concentration of the incubator was adjusted to $1 \%$. EA.hy 926 cells $\left(2 \times 10^{6} / \mathrm{ml}\right)$ cultured in the normal and hypoxic conditions were respectively transfected with miRNA-93 mimics using RNAiMAX Reagent (Thermo Fisher Scientific, Inc.) in accordance with the manufacturer's instructions. Oligonucleotide transfection RNA oligos were chemically synthesized and purified by Shanghai Genepharma Co. Ltd. (Shanghai, China). The following rno-mir-93 agomir sequences were used: Sense, 5'-CAAAGUGCUGUUCGU GAGGUAG-3' and antisense, 5'-ACCUGCACGAACAGC ACUUUGUU-3'. The sequences of the rno-mir-93 agomir negative control used were as follows: Sense, 5'-UUCUCC GAACGUGUCACGUTT-3' and antisense 5'-ACGUGACAC GUUCGGAGAATT-3'. The final concentration of miRNA mimics used for transfection was $100 \mathrm{nM}$, and the cells were harvested at $12 \mathrm{~h}$ for subsequent experimentation.

Cell proliferation, migration and tube formation. In order to assess the functions of transfected cells under hypoxic conditions, cell proliferation, migration and tube formation assays were performed. Cell proliferation was determined using the MTT method (12). Transfected cells were seeded into 96-well plates at 10,000 cells/well and viability was detected. In order to identify transfected cell migration ability, a wound healing assay was performed. Transfected cells were cultured in serum-free medium for $24 \mathrm{~h}$, and an artificial wound was created using a $100-\mu \mathrm{l}$ sterile pipette tip. A total of $24 \mathrm{~h}$ post-wound infliction, the width of the scratch gap was measured using an inverted microscope (magnification, x10). In the tube formation assay, $10 \mu \mathrm{l}$ growth factor-reduced Matrigel was seeded into each well and permitted to polymerize for $30 \mathrm{~min}$ at $37^{\circ} \mathrm{C}$. Subsequently, 10,000 cells were placed on the Matrigel for $24 \mathrm{~h}$ at $37^{\circ} \mathrm{C}$ and images were viewed using an inverted microscope (magnification, $\mathrm{x} 10$ ). A total of three independent detections were performed for each assay, with analysis of five random visual fields for each chamber.

Luciferase reporter assays. The miRNA body map web tool, including EIMMO (http://www.mirz.unibas.ch/ElMMo3/) and miRanda-mirSVR (http://microRNA.org/), was employed to identify potential target genes of miRNA-93. EA.hy926 cells were co-transfected with the wild-type (WT) or mutant (Mut) CDKN1A 3'-UTR reporter genes or negative control miRNA mimics (pMIR-Control; Genscript Cor--p., Piscataway, NJ, USA). Following culture for $36 \mathrm{~h}$, the luciferase activity was determined via comparison with Renilla luciferase activity when the cells had been lysed with a passive lysis buffer, using the Dual-Luciferase Reporter Assay System (Promega Corporation, Madison, WI, USA).

Western blotting. Western blot analysis using EA.hy926 cells was performed as previously described $(21,22)$. The total proteins were incubated with primary antibodies against CDKN1A (1:1,000; cat. no. SAB4300419; Sigma-Aldrich, Merck KGaA, Darmstadt, Germany), and subsequently incubated with a secondary antibody $(1: 2,000$; cat. no. ab6721; Abcam, Cambridge, UK). GAPDH (1:2,000; cat. no. G5262; Sigma-Aldrich; Merck $\mathrm{KGaA}$ ) was used as an internal control. The quantification of the western blotting results was performed using ImageJ software version 1.43 (National Institutes of Health, Bethesda, MD, USA).

Hind-limb ischemic model. $\mathrm{C} 57 \mathrm{Bl} / 6 \mathrm{~J}$ mice $(\mathrm{n}=12)$ weighing $230 \pm 20 \mathrm{~g}$ were purchased from the Institute of Laboratory Animal Sciences, Peking Union Medical College (Beijing, China). All the procedures were approved by the Animal Experimental Ethics Committee, 1st Hospital of Lanzhou University. A critical hind limb ischemia model was created as previously described (23). Prior to surgery, the mice were anesthetized via injection of ketamine $90 \mathrm{mg} / \mathrm{kg}$ and xylazine $10 \mathrm{mg} / \mathrm{kg}$. The ligation and division of the left femoral artery and vein were conducted to surgically create severe unilateral hind limb ischemia. At the time of surgery, mice were randomly divided into two groups ( $\mathrm{n}=6$ per group): The negative control group (NC intramuscular injection); and the miR-93 group (premiR-93 intramuscular injection). PremiR-93 (PM10951) or miR-mimic NC (Genscript Corp.) were dissolved in PBS and intramuscularly injected into the gastrocnemius muscle (100 $\mu \mathrm{M}$ in $25 \mu \mathrm{l}$ ), as previously described (24). Laser Doppler perfusion imaging (LDPI) was conducted 2 weeks post-surgery to detect the blood flow of the ischemic and normal limbs, as previously stated (25). The scores for muscle necrosis and ambulatory impairment were assessed respectively.

Histology. Alterations in muscle tissue morphology were examined with hematoxylin and eosin (H\&E) and platelet endothelial cell adhesion molecule (CD31) staining. The hind limb tissues were fixed in $4 \%$ paraformaldehyde for $48 \mathrm{~h}$ at room temperature, dehydrated, paraffin-embedded and sliced into tissue sections $(4 \mathrm{~mm})$. All the slices were stained using 
$\mathrm{H} \& \mathrm{E}$ and anti-CD31 for histological analysis, according to the manufacturer's specific instructions (26).

Statistical analysis. Descriptive statistics were calculated and are presented as the mean \pm standard error of the mean in the figures. One-way analysis of variance was performed for multiple group comparisons followed by the Student-Newman-Keuls test for group-wise comparisons. The Student's t-test was used for comparison between two groups. $\mathrm{P}<0.05$ was considered to indicate a statistically significant difference. The statistical analysis was performed using SPSS software (SPSS for Windows 17.0; SPSS, Inc., Chicago, IL, USA). A minimum of three repeats were performed per assay.

\section{Results}

Expression levels of miR-93 in patients with PAD. In order to detect the importance of miR-93 in PAD, the expression of miR-93 was analyzed using RT-qPCR. miR-93 expression in patients with PAD was significantly upregulated when compared with the controls (Fig. 1A). It has been demonstrated that PAD severity, as determined by the ABI, is also correlated with the degree of functional impairment $(27,28)$. Among participants able to walk for 6 min without stopping at baseline, the diagnosis of PAD degree was made in accordance with baseline ABI categories $(<0.50 ; 0.50<0.70 ; 0.70<0.90$; and $0.90<1.10)(29)$. Furthermore, to validate the fold-change in miR-93 expression in patients with differing degrees of PAD, corresponding expression of miR-93 was determined, and the results demonstrated that there was a positive association between miR-93 expression and PAD severity (Fig. 1B). Collectively, these findings indicated that miR-93 was involved in the development and progression of PAD.

CDKN1A is a potential target of miR-93. To further identify the underlying mechanism by which miR-93 facilities proliferation, migration and tube formation of EA.hy 926 cells, we verified CDKN1A as a direct target of miR-93 using accessible databases $(30,31)$. The luciferase reporter was constructed, which contained the wild-type or mutant miR-93 target sequences of CDKN1A 3'-UTR. The luciferase reporter assay was performed to demonstrate whether the CDKN1A 3'-UTR is a direct target of miR-93 (Fig. 2A). As indicated in Fig. 2B, compared with the mutant reporter gene, the luciferase activity of the wild-type 3'-UTR reporter gene was significantly downregulated, suggesting that miR-93 is able to bind to the CDKN1A 3'-UTR. It was additionally observed that miR-93 significantly inhibited CDKN1A expression at the mRNA and protein levels, using RT-qPCR and western blotting (Fig. 2C and D). Taken together, these findings demonstrated that miR-93 may directly suppress CDKN1A expression in EA.hy926 cells by targeting the CDKN1A 3'-UTR.

Effects of miR-93 in EA.hy926 cells in response to hypoxia. To examine the effect of miR-93 on endothelial cells under hypoxic conditions, the expression of miR-93 was analyzed using RT-qPCR, and the results demonstrated that miR-93 expression was upregulated in response to hypoxia when compared with normal conditions (Fig. 3A). Additionally, cells were transfected with miR-93, in which the miR-93 level was quantified by

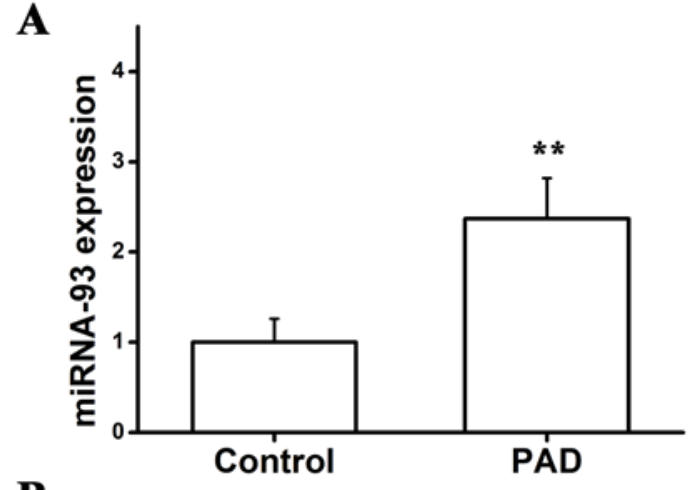

B

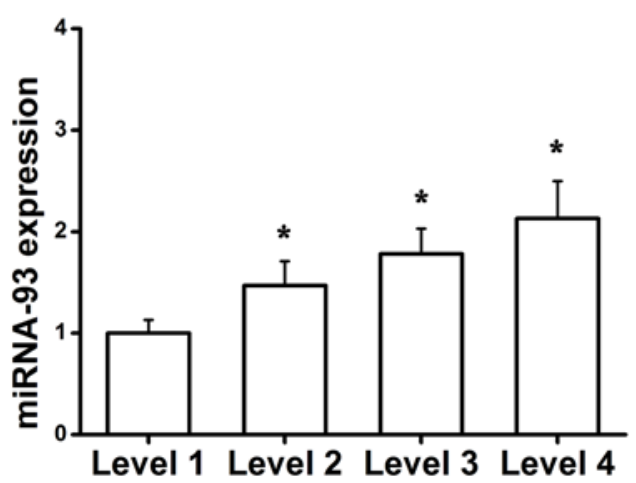

Figure 1. Expression levels of miR-93 in patients with PAD. (A) RT-qPCR analysis of miR-93 expression in patients with PAD $(n=48)$ and controls $(\mathrm{n}=25)$. ${ }^{* *} \mathrm{P}<0.01$ vs. control group. (B) RT-qPCR analysis of miR-93 expression in patients with differing degrees of PAD. ${ }^{*} \mathrm{P}<0.05$ vs. Level 1 . The experiment was repeated three times. RT-qPCR, reverse transcription-quantitative polymerase chain reaction; miR, microRNA; PAD, peripheral arterial disease.

RT-qPCR at $48 \mathrm{~h}$ post-transfection. miR-93 was successfully overexpressed in EA.hy926 cells (Fig. 3B), and a number of experiments were performed in vitro, including the MTT assay, wound healing assay and tube formation assay. The data demonstrated that the proliferation, migration and tube formation of cells that were transfected with miR-93 and cultured in hypoxic conditions were markedly enhanced (Fig. 3C-E). Thus, the aforementioned data suggested that miR-93 maintained endothelial cell activity by promoting proliferation, migration and tube formation in response to hypoxia.

Overexpression of miR-93 in the hind-limb ischemic model to improve perfusion recovery. It has been reported that BALB/cJ mice have decreased expression of miR-93 and exhibit little increase in miR-93 following hind-limb ischemia when compared with C57B1/6J mice (32). Thus, local intramuscular injections of premiR-93 and NC were administered to detect whether the overexpression of miR-93 improved perfusion in the hind-limb ischemic model. The LDPI experiment indicated that miR-93 increased the blood flow ratio and improved tissue necrosis and ambulatory impairment, as presented in Fig. 4A-C. Consistent with improved perfusion recovery, ischemic hind limb muscles from the mice injected with premiR-93 indicated decreased muscle necrosis and a higher capillary density when compared with NC-treated mice (Fig. 4D), suggesting that overexpression of miR-93 may be sufficient to promote angiogenesis following hind-limb ischemia. 
$\mathbf{A}$
CDKN1A 3'-UTR 5' $\ldots$...AGAAGUAAACAGAUGGCACUUUG...
miRNA-93
3. GAUGgACGUGCUUGUCGUGAAAC
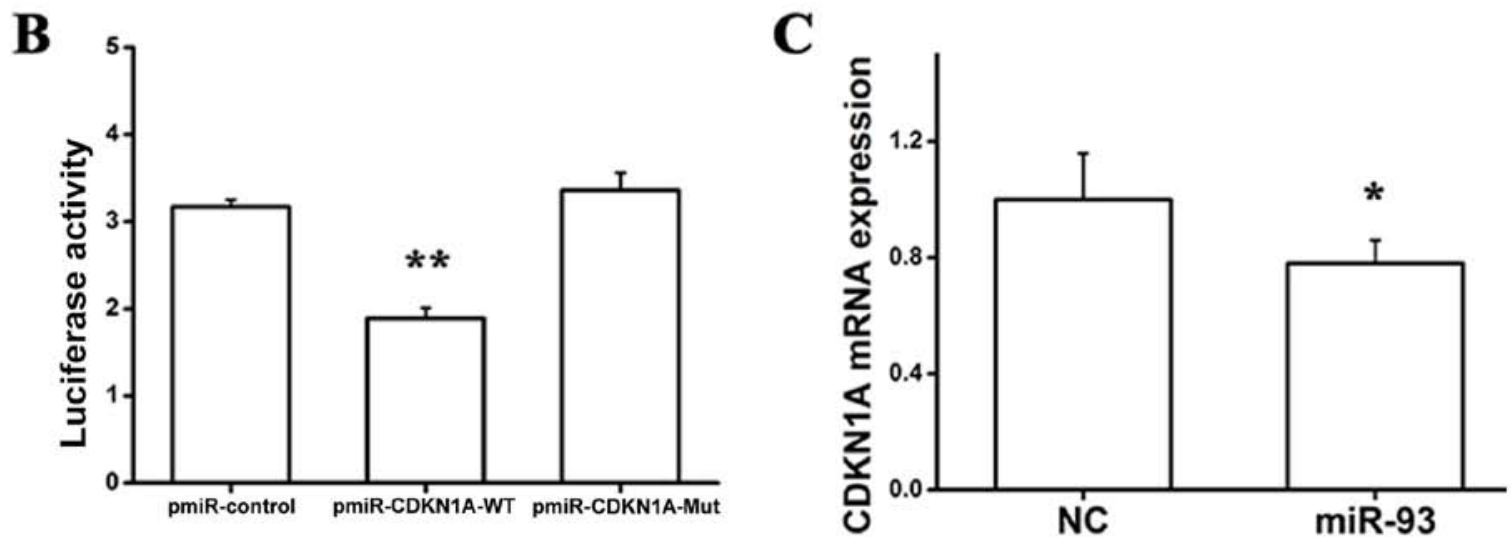

D
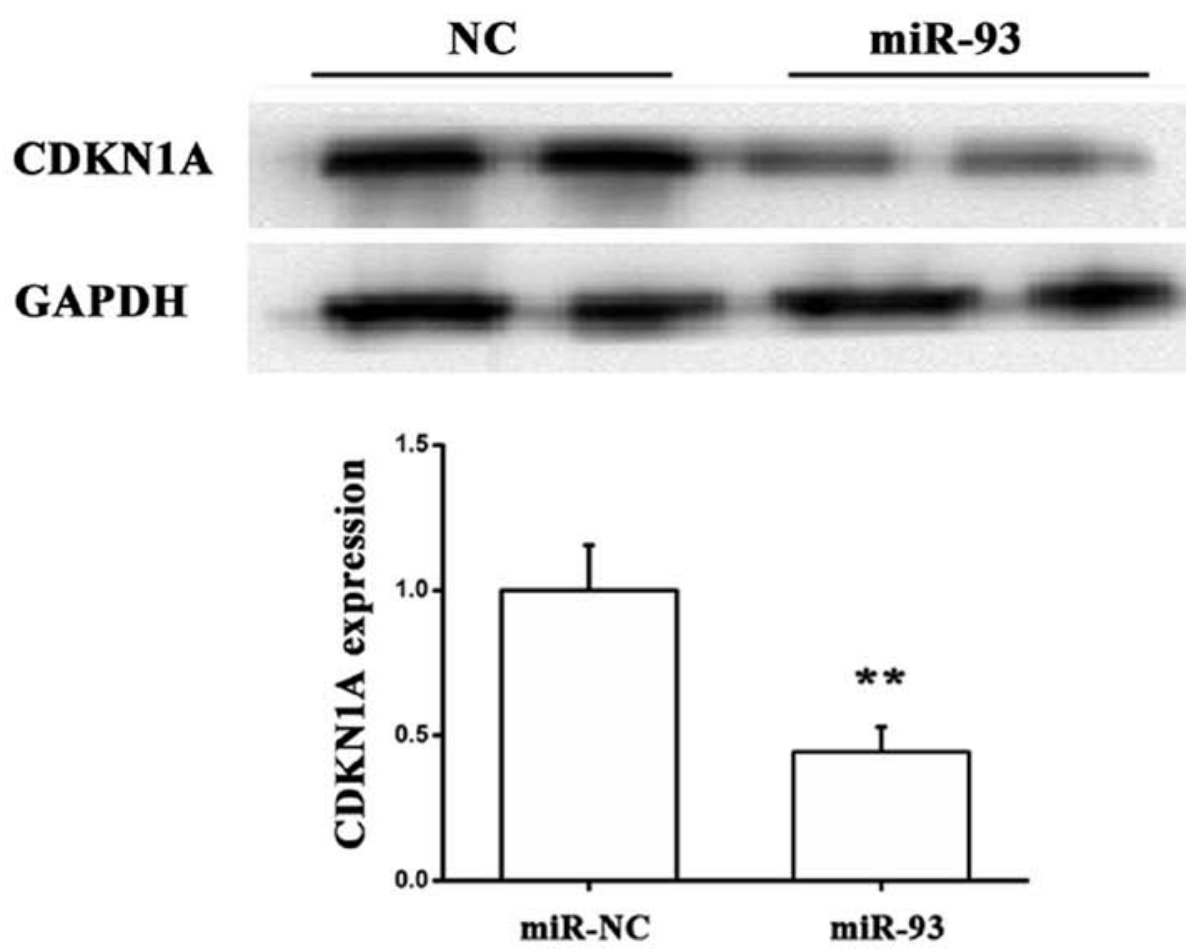

Figure 2. CDKN1A is a potential target of miR-93. (A) Schematic representation of the CDKN1A 3'-UTR as a direct target of miR-93. (B) Luciferase activity of EA.hy926 cells co-transfected with the WT or Mut CDKN1A 3'-UTR reporter genes or negative control miRNA mimics. ** P<0.01 vs. pMIR-CDKN1A-Mut. (C) Quantification of CDKN1A mRNA expression levels by reverse transcription-quantitative polymerase chain reaction. "P<0.05 vs. NC. (D) CDKN1A protein expression was determined by western blotting in EA.hy 926 cells co-transfected with miR-93 or control, and the quantification was performed using Image J. $n=3 .{ }^{* *} \mathrm{P}<0.01$ vs. miR-NC. The experiment was repeated three times. CDKN1A, cyclin dependent kinase inhibitor 1A; miR, microRNA; UTR, untranslated region; NC, negative control; WT, wild-type; Mut, mutant.

\section{Discussion}

The discovery of miRNAs was considered a milestone in molecular biology, and miRNAs are critical regulators involved in numerous cellular processes, including proliferation, migration, apoptosis and differentiation. miRNAs have been closely associated with the development and progression of tumors $(33,34)$. In the present study, miR-93 expression in the peripheral blood of patients with PAD was compared with the control group, and it was observed that miR-93 was upregulated in patients with PAD. To validate the molecular mechanisms underlying PAD, EA.hy926 endothelial cells were used to observe miR-93 expression in response to hypoxia. In vitro analyses demonstrated that miR-93 promoted 
$\mathbf{A}$

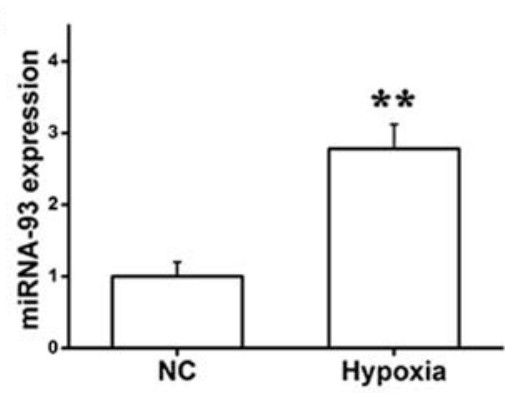

C

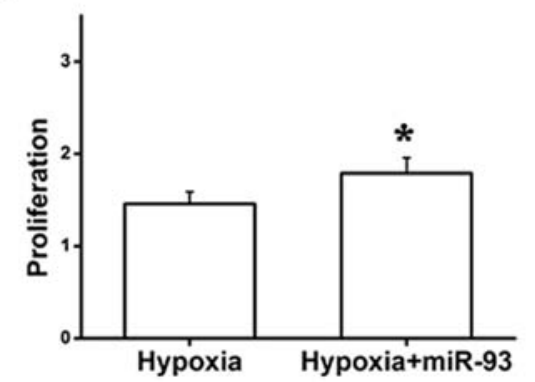

B

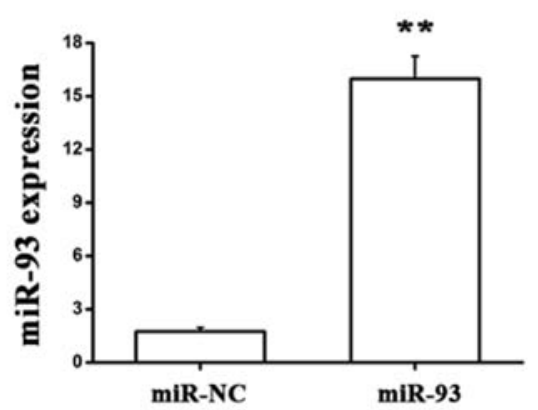

D

$\mathbf{0 ~ h}$

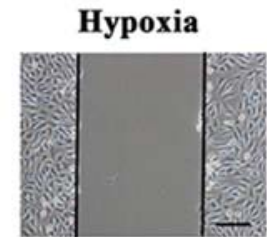

Hypoxia+miR-93

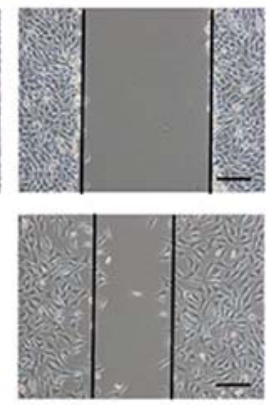

\section{$\mathbf{E}$}

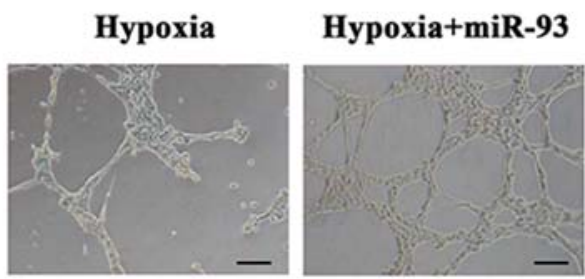

Figure 3. Effects of miR-93 in EA.hy926 cells in response to hypoxia. (A) RT-qPCR analysis of miR-93 expression in EA.hy926 cells when cultured in normal and hypoxic conditions. ${ }^{* *} \mathrm{P}<0.01$ vs. NC. (B) RT-qPCR analysis of miR-93 expression in EA.hy 926 cells transfected with the miR-93 vector. ${ }^{* *} \mathrm{P}<0.01$ vs. NC. (C) The proliferation of cells transfected with miR-93 or the control when cultured in hypoxic conditions was determined using an MTT assay. ${ }^{*}<0.05$ vs. hypoxia. (D) Representative images of cell migration following transfection with miR-93 or the control when cultured in hypoxic conditions at 0 and $12 \mathrm{~h}$. Scale bar, $50 \mu \mathrm{m}$. (E) Representative images of tube formation of cells transfected with miR-93 or the control when cultured in hypoxic conditions for $12 \mathrm{~h}$. Scale bar, $50 \mu \mathrm{m} . \mathrm{n}=3$. The experiment was repeated three times. RT-qPCR, reverse transcription-quantitative polymerase chain reaction; miR, microRNA; $\mathrm{NC}$, negative control.

EA.hy926 cell proliferation, migration and tube formation by binding to CDKN1A, which was demonstrated to be a direct target. The aforementioned findings revealed that miR-93 enhanced the proliferation, migration and tube formation of EA.hy926 cells by directly targeting CDKN1A.

PAD induces tissue hypoperfusion and eventually results in critical limb ischemia (35). A number of miRNAs have been reported to be associated with the development of PAD and involved in vascular disorders. Liu et al (36) reported that miRNA-15b is associated with apoptosis and angiogenesis in myocardial infarction. Kuehbacher et al (37) demonstrated that miR-27b may be regarded as a pro-angiogenic miRNA by regulating angiogenesis through the angiogenic inhibitor, thrombospondin-1. Chamorro-Jorgane et al (38) indicated that miR-16 modulates angiogenic signaling and vascular integrity, serving a role in angiogenesis by suppressing the proliferation, migration and angiogenic capacity of endothelial cells. However, little information is available pertaining to the association between miRNA-93 expression and PAD. The results of the present study revealed that miRNA-93 was upregulated in EA.hy926 endothelial cells when cultured in hypoxic conditions, and in freshly frozen muscle tissues. To further verify the angiogenic function of miRNA-93, the effect of miRNA-93 on endothelial cells was observed in vitro and the results suggested that miRNA-93 may facilitate proliferation, migration and tube formation under hypoxic conditions, indicating that miRNA-93 may contribute to the progression of PAD by regulating endothelial cell activities (32).

In previously established models of PAD, a series of studies $(32,39,40)$ indicated that $\mathrm{C} 57 \mathrm{Bl} / 6 \mathrm{~J}$ mice recover well, while BALB/cJ mice exhibit poor perfusion recovery following hind-limb ischemia. In vivo, $\mathrm{C} 57 \mathrm{Bl} / 6 \mathrm{~J}$ mice were used as a model and it was observed that hind-limb blood perfusion was improved, and scores for muscle necrosis and ambulatory impairment were significantly decreased following injection of premiR-93, which indicated that overexpression of miR-93 promoted angiogenesis to improve recovery from hind-limb ischemia. Furthermore, extensive histological staining of the hind-limb tissue revealed a high density of CD31, which is considered to be a key marker of endothelial cells. Consistent with the results of the in vitro studies $(32,41)$, these findings further confirmed the role of miR-93 in ischemia-induced angiogenesis. 

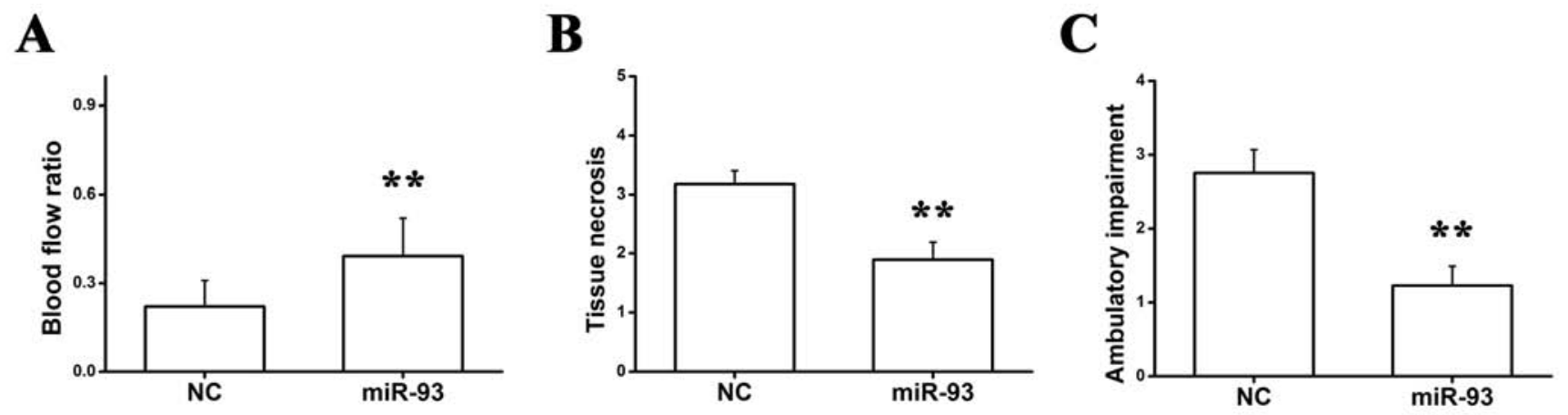

D

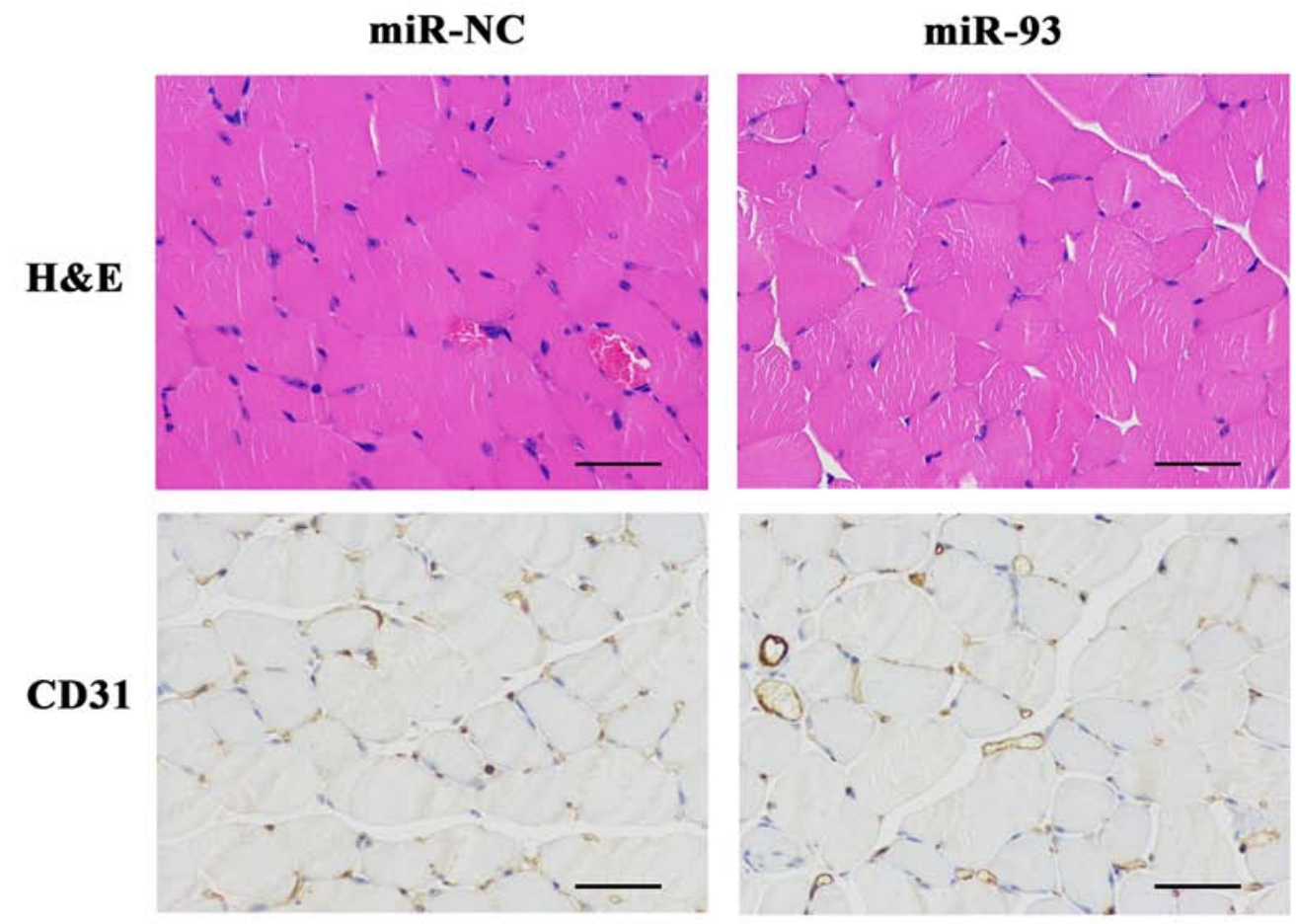

Figure 4. Overexpression of miR-93 in the hind-limb ischemic model to improve perfusion recovery. (A) miR-93 significantly increased the blood flow ratio, and improved (B) tissue necrosis and (C) ambulatory impairment. ${ }^{* *} \mathrm{P}<0.01$ vs. NC. (D) Representative images of H\&E and CD31 staining. Scale bar, $100 \mu \mathrm{m}$. $\mathrm{n}=6$. The experiment was repeated three times. miR, microRNA; H\&E, hematoxylin and eosin; CD31, platelet endothelial cell adhesion molecule; NC, negative control.

CDKN1A is regarded as an important inhibitor of the cell cycle, mediator of DNA damage and effector of the tumor suppressor cellular tumor antigen p53, displaying a key role in the development and progression of various cancer types (42). CDKN1A, an endothelial dysfunction-associated gene, is associated with the decrease in human umbilical vein endothelial cell viability caused by sodium arsenite (43). Yamagata et al (44) reported that docosahexaenoic acid regulates the expression of numerous genes that involve CDKN1A, which is associated with senescence and dysfunction in endothelial cells.

Previous studies have emphasized the functional implications of CDKN1A during the development of PAD $(45,46)$. As previously stated, PAD is an atherosclerotic disease, in which the pathological response contributes to a complex inflammatory reaction induced by endothelial functional loss (45). In the present study, using a luciferase reporter assay, CDKN1A was identified as a direct target of miR-93 in EA.hy926 cells, suggesting that miR-93 exerts an important effect in the regulation of angiogenesis during PAD via binding to CDKN1A.
In conclusion, miR-93 contributes to angiogenesis by enhancing the proliferation, migration and tube formation of EA.hy926 endothelial cells, which is associated with the reduced expression of CDKN1A. Overexpression of miR-93 was able to ameliorate ischemia in the mouse hind-limb, providing a novel opportunity to elucidate whether miR-93/CDKN1A may be a promising therapeutic target for PAD.

\section{Acknowledgements}

Not applicable.

\section{Funding}

The present study was supported by grants from the National Natural Science Foundation of China (grant no. 81770483), the Jiangsu Provincial Science and Technology Office (grant no. BL2014043), and the Suzhou Health and Family Planning Commission Program (grant no. LCZX201504). 


\section{Availability of data and materials}

The datasets used and/or analyzed during the current study are available from the corresponding author on reasonable request.

\section{Authors' contributions}

XS designed the study, performed experiments, analyzed the data and wrote the manuscript. YM performed a number of in vitro and in vivo experiments. ZL performed the animal experiments. WW, YC and SL analyzed the data and drafted the manuscript. XL designed and supervised the study, and edited the manuscript.

\section{Ethics approval and consent to participate}

Written informed consent was obtained from all patients and the experiment was approved by the ethics committee of 1st Hospital of Lanzhou University (Lanzhou, China). All the procedures were performed in accordance with national (D.L.n.26, March 4th, 2014) and international laws and policies (directive 2010/63/EU), and were approved by the Animal Experimental Ethics Committee, 1st Hospital of Lanzhou University.

\section{Patient consent for publication}

Not applicable.

\section{Competing interests}

The authors declare that they have no competing interests.

\section{References}

1. Lentz SR, Sobey CG, Piegors DJ, Bhopatkar MY, Faraci FM, Malinow MR and Heistad DD: Vascular dysfunction in monkeys with diet-induced hyperhomocyst(e)inemia. J Clin Invest 98: 24-29, 1996.

2. Tawakol A, Omland T, Gerhard M, Wu JT and Creager MA: Hyperhomocyst(e)inemia is associated with impaired endothelium-dependent vasodilation in humans. Circulation 95 1119-1121, 1997.

3. Faxon DP, Fuster V, Libby P, Beckman JA, Hiatt WR, Thompson RW, Topper JN, Annex BH, Rundback JH, Fabunmi RP, et al: Atherosclerotic vascular disease conference: Writing group III: Pathophysiology. Circulation 109: 2617-2625, 2004.

4. Criqui MH, Fronek A, Barrett-Connor E, Klauber MR, Gabriel S and Goodman D: The prevalence of peripheral arterial disease in a defined population. Circulation 71: 510-515, 1985.

5. Selvin E and Erlinger TP: Prevalence of and risk factors for peripheral arterial disease in the United States: Results from the National health and nutrition examination survey, 1999-2000. Circulation 110: 738-743, 2004.

6. Norgren L, Hiatt WR, Dormandy JA, Nehler MR, Harris KA, Fowkes FG; TASC II Working Group, Bell K, Caporusso J, Durand-Zaleski I, et al: Inter-society consensus for the management of peripheral arterial disease (TASC II). Eur J Vasc Endovasc Surg 33 (Suppl 1): S1-S75, 2007.

7. Morisaki K, Yamaoka T and Iwasa K: Risk factors for wound complications and 30-day mortality after major lower limb amputations in patients with peripheral arterial disease. Vascular 26 $12-17,2018$

8. Weragoda J, Seneviratne R, Weerasinghe MC and Wijeyaratne SM: Risk factors of peripheral arterial disease: A case control study in Sri Lanka. BMC Res Notes 9: 508, 2016.
9. Forés R, Alzamora MT, Pera G, Valverde M, Angla M, Baena-Díez JM and Mundet-Tuduri X: Evolution and degree of control of cardiovascular risk factors after 5 years of follow-up and their relationship with the incidence of peripheral arterial disease: ARTPER cohort. Med Clin (Barc) 148: 107-113, 2017 (In English, Spanish).

10. Trionfini P and Benigni A: MicroRNAs as master regulators of glomerular function in health and disease. J Am Soc Nephrol 28: 1686-1696, 2017.

11. Kato $M$ and Natarajan R: MicroRNAs in diabetic nephropathy: Functions, biomarkers, and therapeutic targets. Ann N Y Acad Sci 1353: 72-88, 2015

12. Stather PW, Sylvius N, Wild JB, Choke E, Sayers RD and Bown MJ: Differential microRNA expression profiles in peripheral arterial disease. Circ Cardiovasc Genet 6: 490-497, 2013.

13. Fichtlscherer S, De Rosa S, Fox H, Schwietz T, Fischer A, Liebetrau C, Weber M, Hamm CW, Röxe T, Müller-Ardogan M, et al: Circulating microRNAs in patients with coronary artery disease. Circ Res 107: 677-684, 2010.

14. Savita U and Karunagaran D: MicroRNA-106b-25 cluster targets $\beta$-TRCP2, increases the expression of Snail and enhances cell migration and invasion in H1299 (non small cell lung cancer) cells. Biochem Biophys Res Commun 434: 841-847, 2013.

15. Fang L, Deng Z, Shatseva T, Yang J, Peng C, Du WW, Yee AJ, Ang LC, He C, Shan SW and Yang BB: MicroRNA miR-93 promotes tumor growth and angiogenesis by targeting integrin- $\beta 8$. Oncogene 30: 806-821, 2011.

16. Fang L, Du WW, Yang W, Rutnam ZJ, Peng C, Li H, O'Malley YQ, Askeland RW, Sugg S, Liu M, et al: MiR-93 enhances angiogenesis and metastasis by targeting LATS2. Cell Cycle 11: 4352-4365, 2012.

17. Liu S, Patel SH, Ginestier C, Ibarra I, Martin-Trevino R, Bai S, McDermott SP, Shang L, Ke J, Ou SJ, et al: MicroRNA93 regulates proliferation and differentiation of normal and malignant breast stem cells. PLoS Genet 8: e1002751, 2012.

18. Li F, Liang X, Chen Y, Li S and Liu J: Role of microRNA-93 in regulation of angiogenesis. Tumour Biol 35: 10609-10613, 2014.

19. Xu YF, Mao YP, Li YQ, Ren XY, He QM, Tang XR, Sun Y, Liu N and Ma J: MicroRNA-93 promotes cell growth and invasion in nasopharyngeal carcinoma by targeting disabled homolog- 2 . Cancer Lett 363: 146-155, 2015.

20. Liu G, Friggeri A, Yang Y, Park YJ, Tsuruta Y and Abraham E: miR-147, a microRNA that is induced upon Toll-like receptor stimulation, regulates murine macrophage inflammatory responses. Proc Natl Acad Sci USA 106: 15819-15824, 2009.

21. Yang F, Huang XR, Chung AC, Hou CC, Lai KN and Lan HY: Essential role for Smad3 in angiotensin II-induced tubular epithelial-mesenchymal transition. J Pathol 221: 390-401, 2010.

22. Koka V, Huang XR, Chung AC, Wang W, Truong LD and Lan HY: Angiotensin II up-regulates angiotensin I-converting enzyme (ACE), but down-regulates ACE2 via the AT1-ERK/p38 MAP kinase pathway. Am J Pathol 172: 1174-1183, 2008.

23. Sun Q, Chen RR, Shen Y, Mooney DJ, Rajagopalan S and Grossman PM: Sustained vascular endothelial growth factor delivery enhances angiogenesis and perfusion in ischemic hind limb. Pharm Res 22: 1110-1116, 2005.

24. Ge Y, Sun Y and Chen J: IGF-II is regulated by microRNA-125b in skeletal myogenesis. J Cell Biol 192: 69-81, 2011.

25. Couffinhal T, Silver M, Zheng LP, Kearney M, Witzenbichler B and Isner JM: Mouse model of angiogenesis. Am J Pathol 152: 1667-1679, 1998.

26. Bao H, Lv F and Liu T: A pro-angiogenic degradable Mg-poly(lactic-co-glycolic acid) implant combined with rhbFGF in a rat limb ischemia model. Acta Biomaterial 64: 279-289, 2017.

27. McDermott MM, Greenland P, Liu K, Guralnik JM, Celic L, Criqui MH, Chan C, Martin GJ, Schneider J, Pearce WH, et al: The ankle brachial index is associated with leg function and physical activity: The walking and leg circulation study. Ann Intern Med 136: 873-883, 2002.

28. Mcdermott MG, Liu K, Jack M, Guralnik MD, Mehta S, Criqui MH, Martin GJ and Greenland P: The ankle brachial index independently predicts walking velocity and walking endurance in peripheral arterial disease. J Am Geriatr Soc 46: 1355-1362, 1998.

29. McDermott MM, Liu K, Greenland P, Guralnik JM, Criqui MH, Chan C, Pearce WH, Schneider JR, Ferrucci L, Celic L, et al: Functional decline in peripheral arterial disease: Associations with the ankle brachial index and leg symptoms. JAMA 292 : 453-461, 2004. 
30. Lewis BP, Burge CB and Bartel DP: Conserved seed pairing, often flanked by adenosines, indicates that thousands of human genes are microRNA targets. Cell 120: 15-20, 2005.

31. John B, Enright AJ, Aravin A, Tuschl T, Sander C and Marks DS Correction: Human MicroRNA targets. PLoS Biol 2: e363, 2004

32. Hazarika S, Farber CR, Dokun AO, Pitsillides AN, Wang T, Lye RJ and Annex BH: MicroRNA-93 controls perfusion recovery following hind-limb ischemia by modulating expression of multiple genes in the cell cycle pathway. Circulation 127: 1818-1828, 2013.

33. Calin GA and Croce CM: MicroRNA signatures in human cancers. Nat Rev Cancer 6: 857-866, 2006.

34. Huang Q, Gumireddy K, Schrier M, le Sage C, Nagel R, Nair S, Egan DA, Li A, Huang G, Klein-Szanto AJ, et al: The microRNAs miR-373 and miR-520c promote tumour invasion and metastasis. Nat Cell Biol 10: 202-210, 2008.

35. Slovut DP and Sullivan TM: Critical limb ischemia: Medical and surgical management. Vasc Med 13: 281-291, 2008.

36. Liu Z, Yang D, Xie P, Ren G, Sun G, Zeng X and Sun X: MiR-106b and MiR-15b modulate apoptosis and angiogenesis in myocardial infarction. Cell Physiol Biochem 29: 851-862, 2012.

37. Kuehbacher A, Urbich C, Zeiher AM and Dimmeler S: Role of Dicer and Drosha for endothelial microRNA expression and angiogenesis. Circ Res 101: 59-68, 2007.

38. Chamorro-Jorganes A, Araldi E, Penalva LO, Sandhu D, Fernández-Hernando $\mathrm{C}$ and Suárez Y: MicroRNA-16 and microRNA-424 regulate cell-autonomous angiogenic functions in endothelial cells via targeting vascular endothelial growth factor receptor-2 and fibroblast growth factor receptor-1. Arterioscler Thromb Vasc Biol 31: 2595-2606, 2011.

39. Dokun AO, Keum S, Hazarika S, Li Y, Lamonte GM, Wheeler F, Marchuk DA and Annex BH: A quantitative trait locus (LSq-1) on mouse chromosome 7 is linked to the absence of tissue loss after surgical hindlimb ischemia. Circulation 117: 1207-1215, 2008 .
40. Chalothorn D, Clayton JA, Zhang H, Pomp D and Faber JE: Collateral density, remodeling and VEGF-A expression differ widely between mouse strains. Physiol Genomics 30: 179-191, 2007.

41. Long J, Wang Y, Wang W, Chang BH and Danesh FR: Identification of microRNA-93 as a novel regulator of vascular endothelial growth factor in hyperglycemic conditions. J Biol Chem 285: 23457-23465, 2010.

42. Negishi M, Wongpalee S P, Sarkar S, Park J, Lee KY, Shibata Y, Reon BJ, Abounader R, Suzuki Y, Sugano S and Dutta A: A new lncRNA, APTR, associates with and represses the CDKN1A/p21 promoter by recruiting polycomb proteins. PLoS One 9: e95216, 2014.

43. Nuntharatanapong $\mathrm{N}$, Chen K, Sinhaseni P and Keaney JF Jr: EGF receptor-dependent JNK activation is involved in arsenite-induced p21Cip1/Waf1 upregulation and endothelial apoptosis. Am J Physiol Heart Circ Physiol 289: H99-H107, 2005.

44. Yamagata K, Suzuki S and Tagami M: Docosahexaenoic acid prevented tumor necrosis factor alpha-induced endothelial dysfunction and senescence. Prostaglandins Leukot Essent Fatty Acids 104: 11-18, 2016.

45. Yin DX, Zhao HM, Sun DJ, Yao J and Ding DY: Identification of candidate target genes for human peripheral arterial disease using weighted gene co-expression network analysis. Mol Med Rep 12: 8107-8112, 2015.

46. Spinetti G, Cordella D, Fortunato O, Sangalli E, Losa S, Gotti A Carnelli F, Rosa F, Riboldi S, Sessa F, et al: Global remodeling of the vascular stem cell niche in bone marrow of diabetic patients: Implication of the microRNA-155/FOXO3a signaling pathway. Circ Res 11: 510-522, 2013. International (CC BY-NC-ND 4.0) License. 